\title{
Polychaete consumption increased prostaglandin biosynthesis in female Penaeus monodon
}

\author{
Pacharawan Deenarn ${ }^{1}$, Punsa Tobwor ${ }^{1}$, Vanicha Vichai ${ }^{1}$, Suwanchai Phomklad ${ }^{2}$, \\ Panomkorn Chaitongsakul2, Rungnapa Leelatanawit ${ }^{1,+}$ and Wananit Wimuttisuk@1 \\ ${ }^{1}$ National Center for Genetic Engineering and Biotechnology (BIOTEC), National Science and Technology \\ Development Agency (NSTDA), Khlong Luang, Pathum Thani, Thailand and '2Shrimp Genetic Improvement Center, \\ Chaiya, Surat Thani, Thailand
}

Correspondence should be addressed to WWimuttisuk; Email: wananit.wim@biotec.or.th

${ }^{\dagger}(\mathrm{R}$ Leelatanawit is now at Thermo Fisher Scientific (Thailand), Wattana, Bangkok, Thailand)

\begin{abstract}
The polychaete Perinereis nuntia is preferred over commercial feed pellets for boosting ovarian maturation of the female black tiger shrimp Penaeus monodon. High levels of prostaglandins in polychaetes are believed to enhance shrimp ovarian development. However, the impact of polychaete feeding on shrimp prostaglandin biosynthesis and fatty acid regulatory pathways have yet to be investigated. As polychaetes contain higher levels of arachidonic acid (ARA), eicosapentaenoic acid (EPA), prostaglandin $E_{2}$ (PGE $E_{2}$ ) and prostaglandin $\mathrm{F}_{2 \alpha}\left(\mathrm{PGF}_{2 \alpha}\right)$ than feed pellets, we examined the effects of polychaete feeding alone and in combination with eyestalk ablation on shrimp hepatopancreases and ovaries. Shrimp fed with polychaetes contained higher levels of EPA, PGE ${ }_{2}$ and PGF $_{2 \alpha}$ in hepatopancreases than those of pellet-fed shrimp. Similarly, higher levels of ARA and higher transcription levels of cyclooxygenase (COX) and prostaglandin F synthase (PGFS) were detected in ovaries of polychaete-fed shrimp compared to those of pellet-fed shrimp. The combination of polychaete-feeding and eyestalk ablation, commonly practiced to induce ovarian development, increased levels of ARA and EPA and transcription levels of COX in hepatopancreases and ovaries of polychaete-fed shrimp compared to those of pellet-fed shrimp. In ovaries, prostaglandin biosynthesis gene transcripts were induced by polychaete feeding while transcriptional levels of fatty acid regulatory genes were regulated by shrimp feed and eyestalk ablation. Our findings not only elucidate the effects of polychaete consumption on shrimp prostaglandin biosynthesis and fatty acid regulatory pathways during larvae production, but also suggests that high levels of dietary ARA, EPA and prostaglandins are essential during P. monodon ovarian development.
\end{abstract}

Reproduction (2020) $\mathbf{1 6 0} 873-885$

\section{Introduction}

Domestication of the black tiger shrimp Penaeus monodon has always been hindered by low ovarian maturation rates in female broodstock (Benzie 1997). Prostaglandin levels are thought to be significant factors, with their roles in crustacean ovarian maturation being investigated in several species. The amount of prostaglandin $E_{2}\left(P E_{2}\right)$ in ovaries has been observed to increase during ovary development in the Florida crayfish Procambarus paeninsulanus, the freshwater field crab Oziotelphusa senex senex and P. monodon (Spaziani et al. 1993, Reddy et al. 2004, Meunpol et al. 2010, Wimuttisuk et al. 2013). In contrast, PGE $_{2}$ amounts decrease as oocytes mature in the freshwater prawn Macrobrachium rosenbergii and the kuruma prawn Marsupenaeus japonicus (Tahara \& Yano 2004, Sumpownon et al. 2015). The correlation between prostaglandin levels and oocyte maturation have been demonstrated in vitro, with incubation of P. monodon oocytes in cell culture media spiked with synthetic $\mathrm{PGE}_{2}$ or prostaglandin-rich polychaete extracts increasing the numbers of vitellogenic and mature oocytes (Meunpol et al. 2010). Similarly, injections of $\mathrm{PGE}_{2}$ or prostaglandin $\mathrm{F}_{2 \alpha}\left(\mathrm{PGF}_{2 \alpha}\right)$ in $O$. senex senex and $\mathrm{PGE}_{2}$ in $M$. rosenbergii increased the gonadosomatic index (GSI) values in these crustaceans (Reddy et al. 2004, Sumpownon et al. 2015).

Although prostaglandins have been shown to improve crustacean ovarian development, these prostaglandins were administered artificially. In hatcheries and shrimp farms, prostaglandins can be administered through feeding with polychaetes, with the ingested nutrients being stored and metabolized in hepatopancreases (Vogt 1994, Wen et al. 2001). Use of the polychaete Perinereis nuntia as shrimp feed is preferred as it contains the highest amount of $\mathrm{PGE}_{2}$ among various live feeds, including mud polychaetes, horse mussels, squids and clams (Meunpol et al. 2010). Polychaetes 
also contain higher amounts of arachidonic acid (ARA), a lipid precursor of prostaglandins, than other live feed (Meunpol et al. 2010, Chimsung 2014). Polychaete consumption has been shown to increase the amounts of ARA in hepatopancreases of $M$. japonicus (Binh et al. 2008). Increasing lipid content in crustacean hepatopancreases correlated with transcriptional changes in the fatty acid regulatory pathway, including beta-oxidation, metabolism, synthesis and transport in the Chinese mitten crab Eriocheir sinensis, the swimming crab Portunus trituberculatus, the Pacific white shrimp Penaeus vannamei and P. monodon (Chen et al. 2015, Wei et al. 2017, Deenarn et al. 2018, Yuan et al. 2019).

In this study, comparative analysis was performed to examine changes in the prostaglandin biosynthesis and fatty acid regulatory pathways due to shrimp feed. These changes were monitored in intact shrimp and after eyestalk ablation was performed, which resulted in shrimp with different stages of ovarian development. Together, our work provides new insights into metabolic and transcriptional changes that occur in female broodstock in the context of hatcheries and shrimp farms.

\section{Materials and methods \\ Ethical statement}

Shrimp trials and experiments in this study were approved by the Institutional Animal Care and Use Committee of the National Center for Genetic Engineering and Biotechnology, Thailand. All experiments were performed in accordance with Animal Research: Reporting of In Vivo Experiments (ARRIVE) and conformed with international and national legal and ethical requirements (Elwood et al. 2009, Kilkenny et al. 2010). Shrimp were anesthetized by hypothermia to avoid animal suffering before dissections were performed.

\section{Shrimp rearing and feed experiment}

Eleven-month-old female domesticated P. monodon with an average body weight of $65.8 \pm 14.0 \mathrm{~g}$ was transferred from earthen ponds and acclimated in six concrete tanks $(n=32$ shrimp per tank) for 11 days before the experiment began. Shrimp density was maintained at $2.5 \mathrm{shrimp} / \mathrm{m}^{2}$. Shrimp were fed with B2 commercial feed pellets (Charoen Pokphand Food Public Company, Ltd., Bangkok, Thailand) and maintained in seawater at $30 \mathrm{ppt}$ and $27^{\circ} \mathrm{C}$. Ammonium, nitrite and nitrate levels, alkalinity and $\mathrm{pH}$ were monitored and adjusted twice a week as previously described (Deenarn et al. 2018).

Shrimp in three concrete tanks were fed with B2 commercial feed pellets and the rest was fed with fully mature $P$. nuntia at $2-10 \%$ of the shrimp body weight for 4 weeks, depending on the consumption rate. Intact shrimp were collected at week 0 (W0, $n=3$ per tank) and at the end of week 4 (W4, $n=3$ per tank). Unilateral eyestalk ablation was performed at the end of week 4 and broodstocks were maintained for 9 days. Sample collection occurred on days 1, 4, 7 and 9 (Supplementary Fig. 1, see section on supplementary materials given at the end of this article). Shrimp body weights and lengths were measured and recorded. Hepatopancreases and ovaries were dissected, weighed and snap-frozen in liquid $\mathrm{N}_{2}$.

The GSI of each broodstock was calculated using the following equation:

$$
\text { GSI }=\frac{\text { ovary weight }}{\text { body weight }} \times 100
$$

The ovarian developmental stage of each broodstock was assigned based on the GSI value: stage 1 (GSI < 2), stage 2 $(\mathrm{GSI}=2-3.99)$, stage $3(\mathrm{GSI}=4-6)$ and stage $4(\mathrm{GSI}>6)$. The hepatosomatic index (HSI) was calculated using the following equation:

$$
\text { HSI }=\frac{\text { hepatopancreas weight }}{\text { body weight }} \times 100
$$

\section{Nutritional analysis of shrimp feed}

Fifty grams of feed pellets and polychaetes were sampled daily. Feed samples were pooled in a weekly batch and submitted for approximation and fatty acid profile analysis using gas chromatography-flame ionization detector (GC-FID) at the Central Laboratory (Thailand) Co., Ltd (Songkla, Thailand). Approximation was performed according to the Association of Official Agricultural Chemists (AOAC) guidelines. GC analyses were carried out using Agilent 6890N GC-FID (Agilent) equipped with a capillary column $(100 \mathrm{~m} \times 0.25 \mathrm{~mm}$ i.d., $0.2 \mu \mathrm{m}$, Supelco, Pennsylvania, USA). Detection and injection temperatures were set at $250^{\circ} \mathrm{C}$. The flow rate of carrier gas (He) was set at $1.1 \mathrm{~mL} / \mathrm{min}$. Samples were compared with the standard fatty acid Supelco 37 component fatty acid methyl ester mixture using the in-house method TE-CH-208 based on AOAC guideline 996.06 (DeVries et al. 1999).

\section{Extraction of polyunsaturated fatty acids (PUFAs) from shrimp tissues}

Shrimp ovaries and hepatopancreases were homogenized and adjusted to $0.2 \mathrm{~g}$ tissue/mL in Hank's balanced salt solution (HBSS) at $720 \mathrm{mmol} / \mathrm{kg}$ osmolarity (Sigma-Aldrich). Tissue homogenates were extracted twice with an equal volume of ethyl acetate. The solvent phases were pooled, dried under vacuum and dissolved in 5\% methanol. The extracts were loaded onto 6-mL C18 SPE cartridges (VertiPakTM, Vertical Chromatography, Co., Ltd., Thailand), which were pre-washed with $10 \mathrm{~mL}$ of methanol and $10 \mathrm{~mL}$ of water. Columns were then washed with $10 \mathrm{~mL}$ water, $4 \mathrm{~mL}$ hexane, and again with $10 \mathrm{~mL}$ water. Samples were eluted using $10 \mathrm{~mL}$ of ethyl acetate. The eluate was dried under vacuum and dissolved in ethanol for the reverse-phase HPLC (RP-HPLC) analysis.

\section{Lipid composition analysis of organ extracts using RP-HPLC}

Organ extracts were analyzed using RP-HPLC on an Acclaim ${ }^{\circledR}$ 120 C18 column $(3 \mu \mathrm{m}, 4.6 \mathrm{~mm} \times 150 \mathrm{~mm}$ ) (DIONEX, Surrey, UK). 
The mobile phase consisted of $0.01 \%$ acetic acid in water (solvent A) and $0.01 \%$ acetic acid in acetonitrile (solvent B). The gradient program started with $30 \%$ solvent $B$ and increased to $100 \%$ solvent B within 35 min. ARA, eicosapentaenoic acid (EPA) and docosahexaenoic acid (DHA) were detected using the DIONEX ultimate 3000 diode-array detector (DIONEX) and the amounts of ARA, EPA and DHA were calculated using the standard curve method as previously described (Wimuttisuk et al. 2013, 2017).

\section{Enzyme immunoassay}

Polychaetes, feed pellets, shrimp ovaries and hepatopancreases were homogenized in HBSS. Homogenates were centrifuged at $12,000 \mathrm{~g}$ for $2 \mathrm{~min}$ at $4^{\circ} \mathrm{C}$ to remove cell debris. Amounts of $\mathrm{PGE}_{2}$ and $\mathrm{PGF}_{2 \alpha}$ in the supernatant were estimated using the $\mathrm{PGE}_{2}$ and $\mathrm{PGF}_{2 \alpha}$ enzyme immunoassay (EIA) kits (Cayman Chemical ), respectively. Dose-response curves were generated with $\mathrm{PGE}_{2}$ and $\mathrm{PGF}_{2 \alpha}$ standards at concentrations ranging from 15.63-250.00 pg/mL to $7.80-250.00 \mathrm{pg} / \mathrm{mL}$, respectively. Limits of quantification were $15.63 \mathrm{pg} / \mathrm{mL}$ and $7.80 \mathrm{pg} / \mathrm{mL}$ for $\mathrm{PGE}_{2}$ and $\mathrm{PGF}_{2 \alpha^{\prime}}$ respectively. The average intra-day coefficient of variance $(\mathrm{CV})$ of all controls was $6.41 \%$ for $\mathrm{PGE}_{2}$ and $7.69 \%$ for $\mathrm{PGF}_{2 \alpha}$. The average inter-day $\mathrm{CV}$ of all controls was $7.57 \%$ for $\mathrm{PGE}_{2}$ and $10.50 \%$ for $\mathrm{PGF}_{2 \alpha}$. For the $\mathrm{PGE}_{2}$ EIA kit, percent cross reactivity was $0.07 \%$ for $\mathrm{PGF}_{2 \alpha}$ and less than $0.001 \%$ for prostaglandin $\mathrm{D}_{2}\left(\mathrm{PGD}_{2}\right)$ and $\mathrm{ARA}$. For the $\mathrm{PGF}_{2 \alpha}$ EIA kit, percent cross reactivity was $0.66 \%$ for $\mathrm{PGE}_{2}$ and less than $0.001 \%$ for $\mathrm{PGD}_{2}$ and $\mathrm{ARA}$.

\section{RNA extraction and CDNA synthesis}

Hepatopancreases and ovaries were subjected to total RNA extraction using the Trizol reagent (Invitrogen) and DNase treatment using RNase-free DNase (Promega). Total RNA was reverse transcribed using the RevertAid ${ }^{\mathrm{TM}}$ first strand CDNA Synthesis Kit with oligo (dT) 18 primers (Thermo Scientific).

\section{Quantitative real-time PCR analysis}

Quantitative real-time PCR analysis (qPCR) was performed on individual cDNA samples using the SsoFast EvaGreen Supermix (Bio-Rad) according to the manufacturer's instructions. Primer sequences for prostaglandin biosynthesis and fatty acid regulatory genes are provided in Supplementary Table 1. Melt curve analysis for each primer pair was performed as previously described (Deenarn et al. 2018). Amounts of target gene transcripts relative to that of elongation factor $1 \alpha$ (EF1A) were obtained using the standard curve method. Nine biological replicates were used for each time point and ovarian maturation stage $(n=9)$, except for the eyestalk-ablated, pelletfed shrimp with stage 2 ovaries $(n=5)$.

\section{Statistical analyses}

Significant differences between the means of independent samples from the two feed groups were assessed using the $t$-test with the threshold for significance set at $P<0.05\left(^{*}\right)$ or $P<0.01(* *)$. Other statistical analyses were performed using Dunnett's test to determine the significance between mean differences of designated samples. The thresholds for significance of the Dunnett's test were set at $P<0.05\left({ }^{\#},{ }^{\dagger}\right.$ and $\left.{ }^{\$}\right)$ and $P<0.01\left(\#,{ }^{+\dagger}\right.$ and $\$$ \$).

\section{Results}

\section{Nutritional analysis of shrimp feed}

Approximation analysis of shrimp feed revealed that polychaetes contained greater amounts of fat but less ash than feed pellets (Fig. 1A). Moisture, protein and fiber levels were comparable between the two feed types. GC-FID analysis revealed that feed pellets contained higher levels of six saturated fatty acids (C12:0, C14:0, C20:0, C22:0, C23:0 and C24:0), two monounsaturated fatty acids (C22:1n9 and C24:1n9) and three polyunsaturated fatty acids (C18:3n6, C20:3n3 and C22:6n3) than polychaetes (Supplementary Table $2)$. In contrast, polychaetes contained higher levels of 13 fatty acids, including ARA (C20:4n6) and EPA (C20:5n3), than feed pellets (Fig. 1B). The levels of $\mathrm{PGE}_{2}$ and PGF $_{2 \alpha^{\prime}}$ which are products of ARA, were also higher in polychaetes than feed pellets (Fig. 1C).

\section{Effects of shrimp feed on shrimp body weight, hepatosomatic index and ovarian development}

Intact shrimp collected at W0 and W4 contained stage 1 ovaries regardless of feed type (Fig. 1D and E). After the eyestalk ablation was performed, pellet-fed shrimp reached stage 1 and 2 ovaries while polychaete-fed shrimp were able to reach all four ovarian maturation stages. Shrimp body weights were comparable between the polychaete- and pellet-fed groups at every time point (Fig. 1F). On the other hand, the color and size of hepatopancreases were different between shrimp fed with feed pellets and polychaetes (Fig. 1G). The average hepatosomatic index (HSI) of shrimp fed with polychaetes was also higher than those fed with feed pellets after 4 weeks of feeding and in eyestalk-ablated samples (Fig. 1H).

\section{Changes in hepatopancreases of intact shrimp}

To determine whether the amounts of ARA, EPA and DHA in shrimp hepatopancreases were affected by shrimp feed, RP-HPLC analysis was performed on hepatopancreases of intact shrimp collected at W0 and W4. At W4, levels of EPA in hepatopancreases of polychaete-fed shrimp were higher than those of pelletfed shrimp (Fig. 2B). Additionally, levels of ARA, EPA and DHA in hepatopancreases of polychaete-fed shrimp at W4 were also higher than those at W0 (Fig. 2A, B and C). RT-qPCR analysis was also performed on these samples, revealing that hepatopancreases of polychaetefed shrimp at W4 showed increased transcription levels 

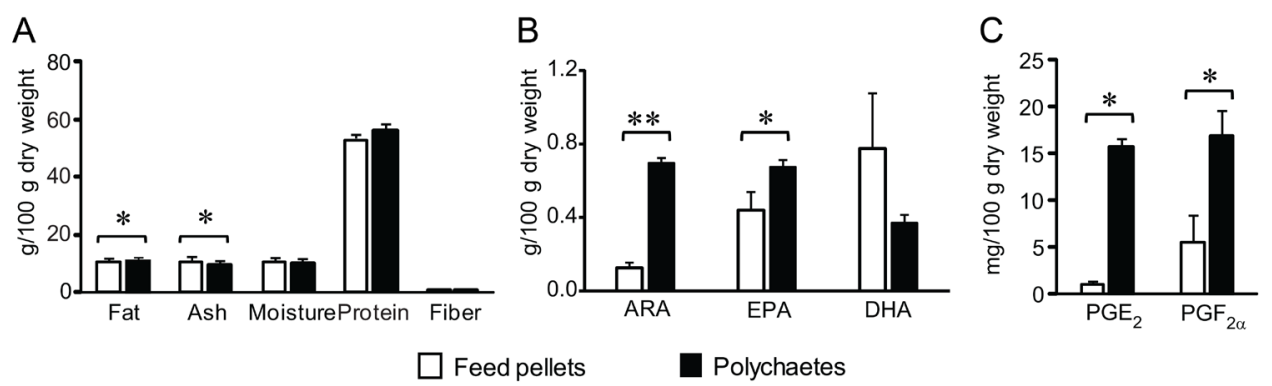

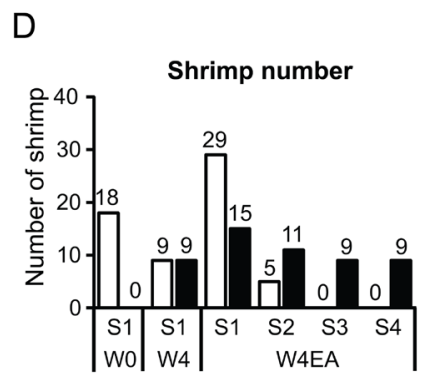

G

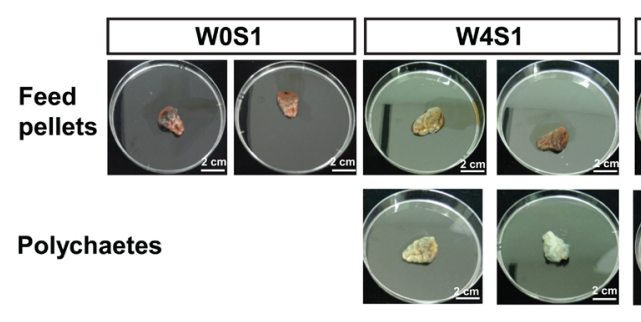

Pellet-fed shrimp
E

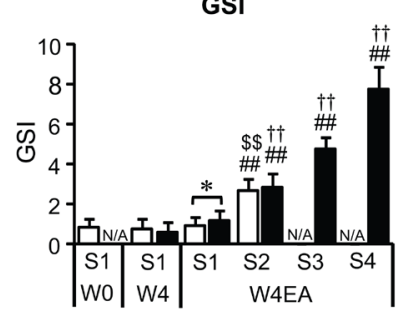

F

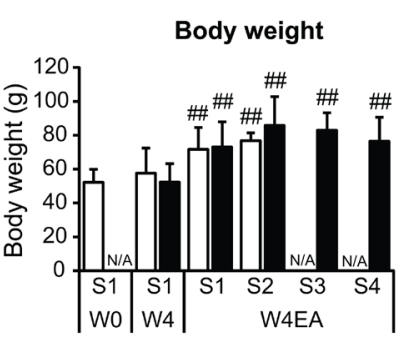

$\mathrm{H}$

$\mathrm{H} \quad$ HSI

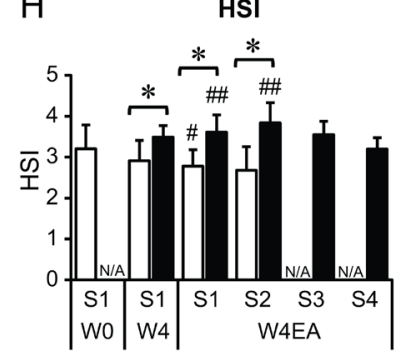

Figure 1 Nutritional assessment of shrimp feed and their effects on shrimp body weight, GSI and HSI. (A, B and C) Fifty grams of feed pellets and polychaetes were collected daily during the feed trial and pooled in a weekly group for analysis $(n=5)$. (A) Nutritional analysis of feed pellets and polychaetes was performed to determine the amounts of fat, ash, moisture, protein and fiber. (B) Levels of ARA, EPA and DHA in shrimp feed were determined. (C) Levels of $\mathrm{PGE}_{2}$ and $\mathrm{PGF}_{2 \alpha}$ in shrimp feed were determined using enzyme immunoassays. (D) The number of shrimp, (E) average GSI values and (F) average shrimp body weights were analyzed according to feed groups, time points and ovarian maturation stages. (G) Shrimp hepatopancreases collected from shrimp with stage 1 ovaries that were fed with feed pellets (top panel) and polychaetes (bottom panel) at week 0 (W0S1), after 4 weeks of feeding (W4S1) and after eyestalk ablation (W4EAS1). (H) Average HSI values of shrimp from different feed groups, time points and ovarian maturation stages. Error bars indicate standard deviations. Asterisks indicate significant differences between feed pellets and polychaetes at $P<0.05$.\#,\#\#Significant differences between the designated condition and the control at W0 at $P<0.05$ and $P<0.01$, respectively. \$Significant differences between the marked condition and the pellet-fed shrimp at W4EAS1 at $P<0.01$. ++ Significant differences between the marked condition and the polychaete-fed shrimp at W4EAS1 at $P<0.01$. N/A indicates that the shrimp sample was not available in the marked stage. Different ovarian maturation stages were shown as S1 for stage 1, S2 for stage 2, S3 for stage 3 and S4 for stage 4.

of cytosolic phospholipase A2 (CPLA2) and prostaglandin $\mathrm{F}$ synthase (PGFS) but decreased transcription levels of cyclooxygenase (COX) when compared to those of pellet-fed shrimp at W4 (Fig. 2D, E and I). No significant difference was observed for genes involved in $\mathrm{PGE}_{2}$ production, namely prostaglandin E synthase 1 (PGES1), prostaglandin E synthase 2 ( $P G E S 2)$ and prostaglandin $\mathrm{E}$ synthase 3 (PGES3) (Fig. 2F, G and H). However, levels of $\mathrm{PGE}_{2}$ and $\mathrm{PGF}_{2 \alpha}$ in hepatopancreases of polychaetefed shrimp were 15 and 12 times higher than those in pellet-fed shrimp, respectively (Fig. 2J and K).
Due to different fatty acid profiles in shrimp feed, changes in fatty acid regulatory gene expression were examined in shrimp hepatopancreases after 4 weeks of feeding. Hepatopancreases of polychaete-fed shrimp contained higher transcription levels of stearoyl-CoA desaturase $(S C D)$ and lower transcriptional levels of enoyl-CoA hydratase $(E C H)$ than those of pellet-fed shrimp (Fig. 3A and I). Additionally, transcription levels of two fatty acid transport genes, long-chain fatty acid transport protein 4 (FATP4) and fatty acid-binding protein $(F A B P)$, also increased as feeding time progressed 
A

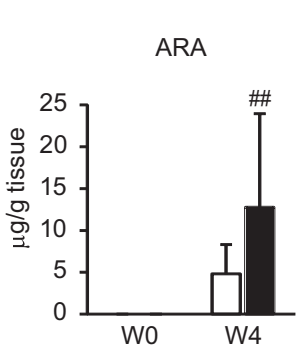

D

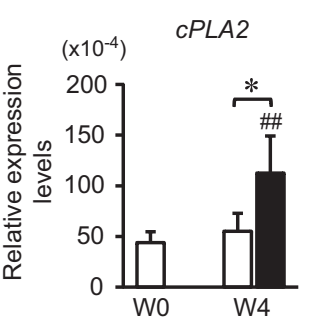

G

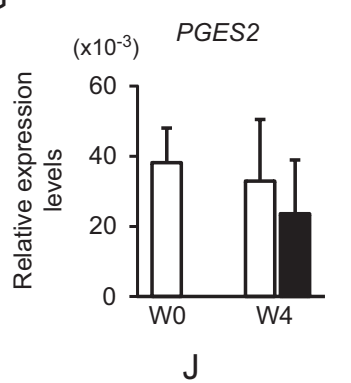

B

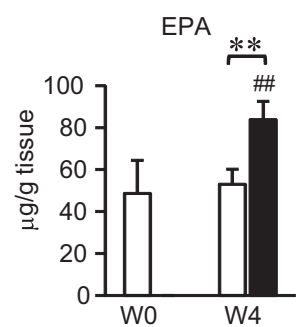

E

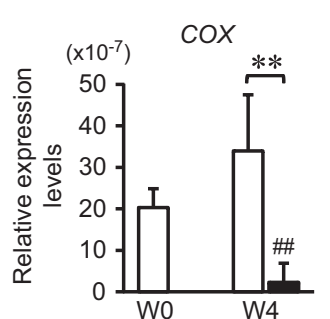

$\mathrm{H}$

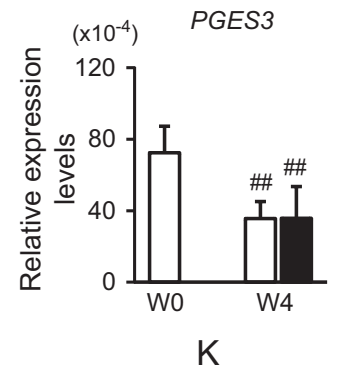

C

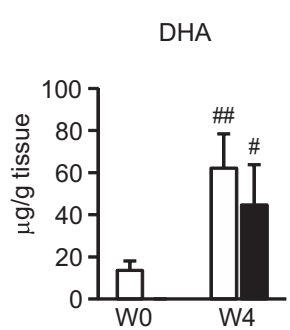

$\mathrm{F}$

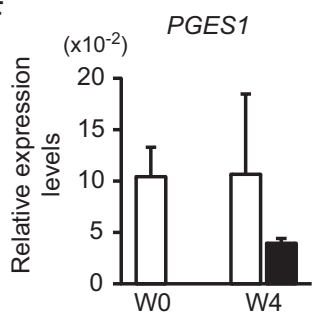

I

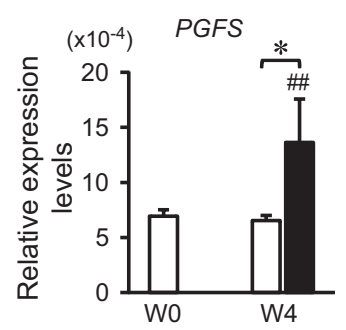

Figure 2 Effects of shrimp feed on the prostaglandin biosynthesis pathway in shrimp hepatopancreases. Shrimp hepatopancreases were collected at the beginning of the feed experiment when shrimp were only fed with feed pellets (W0, $n=18$ ) and again after shrimp were fed with either feed pellets (white bars, $n=9$ ) or polychaetes (black bars, $n=9$ ) for 4 weeks (W4). All shrimp samples contained stage 1 ovaries. Levels of (A) ARA, (B) EPA and (C) DHA in hepatopancreases were determined. Expression levels of (D) CPLA2, (E) COX, (F) PGES1, (G) PGES2, (H) $P G E S 3$ and (I) PGFS in shrimp hepatopancreases were determined using RT-qPCR and expressed relative to EF1A. Levels of (J) $\mathrm{PGE}_{2}$ and $(\mathrm{K}) \mathrm{PGF}_{2 \alpha}$ in shrimp hepatopancreases were determined using enzyme immunoassays. Error bars indicate standard deviations. ${ }^{* * * *}$ Significant differences between feed pellets and polychaetes at $P<$

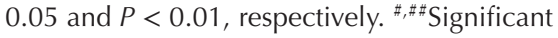
differences between the designated condition and the control at $\mathrm{W} 0$ at $P<0.05$ and $P<$ 0.01 , respectively. from W0 to W4 in hepatopancreases of polychaete-fed shrimp (Fig. 3E and F).

\section{Effects of shrimp feed on ovaries of intact shrimp}

Ovaries of polychaete-fed shrimp contained higher levels of ARA and lower levels of DHA than those of pellet-fed shrimp at W4. (Fig. 4A and C). Transcription levels of COX, PGES3 and PGFS in ovaries of polychaetefed shrimp were higher than those of pellet-fed shrimp (Fig. $4 \mathrm{E}, \mathrm{H}$ and $\mathrm{I}$ ). On the other hand, transcription levels of CPLA2, PGES1 and PGES2 and levels of PGE and $\mathrm{PGF}_{2 \alpha}$ in ovaries were not affected by shrimp diet (Fig. 4D, F, G, J and K). Ovaries of polychaete-fed shrimp showed higher transcription levels of $S C D$, lipophorin receptor $(L P R)$, long-chain fatty acid transport protein 1 (FATP1), FATP4 and ECH than those of pellet-fed shrimp (Fig. 5A, C, D, E and I). In contrast, transcription levels of fatty acid synthase (FASN) in ovaries of polychaetefed shrimp were lower than those of pellet-fed shrimp (Fig. 5B).

\section{Combined effects of shrimp feed and eyestalk ablation on shrimp hepatopancreases}

During shrimp larvae production, a combination of polychaete feeding and eyestalk ablation is required to induce successful ovarian development. Due to the lack of eyestalk-ablated, pellet-fed shrimp with stage 3 and 4 ovaries, the combined effects of shrimp feed and eyestalk ablation were determined only in shrimp with stage 1 and 2 ovaries. Hepatopancreases of polychaetefed shrimp with stage 1 ovaries contained higher levels of ARA while those with stage 2 ovaries contained higher levels of EPA and DHA compared to those of pellet-fed shrimp (Fig. 6A, B and C). Higher transcription levels of COX and PGES3, but lower transcription levels of PGES1 were detected in hepatopancreases of polychaete-fed shrimp with stage 1 ovaries compared to those of pellet-fed shrimp (Fig. 6E, F and H). When shrimp reached stage 2 ovaries, transcription levels of all six prostaglandin biosynthesis genes were comparable in hepatopancreases of shrimp from both feed groups 
A

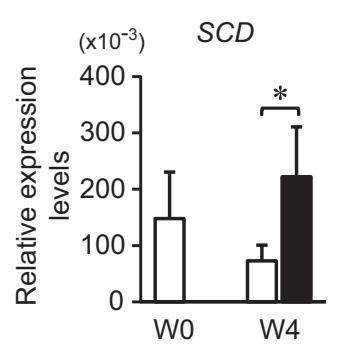

D

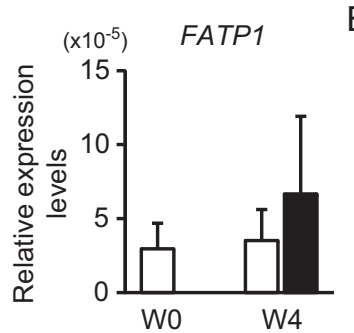

G

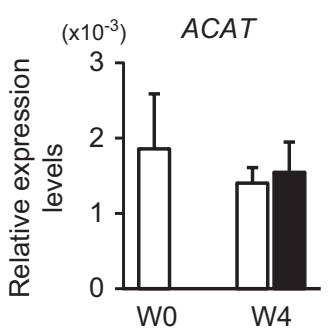

B

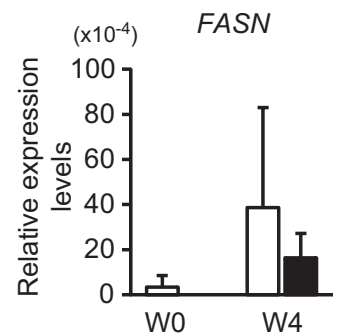

E

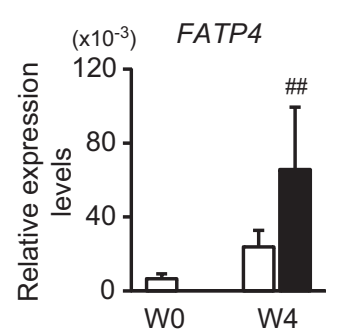

$\mathrm{F}$
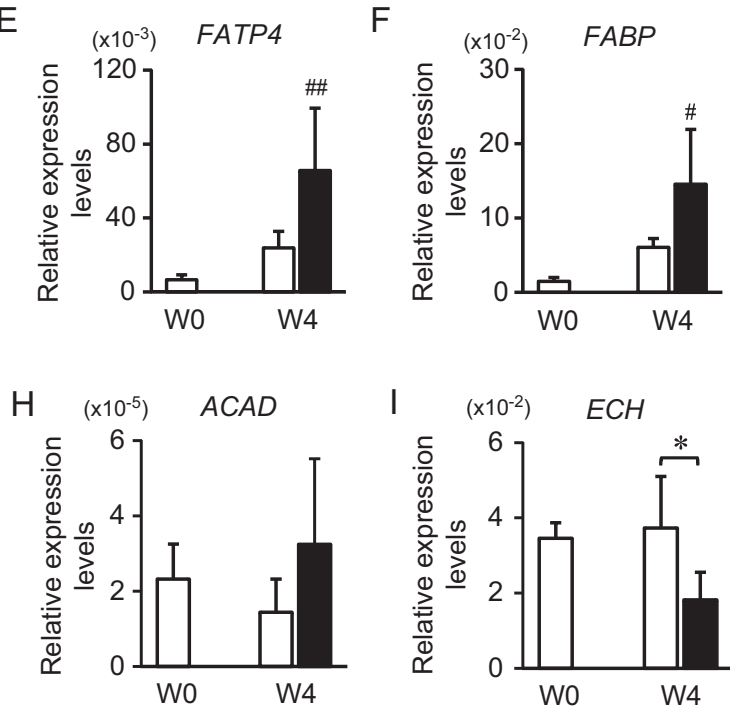

C

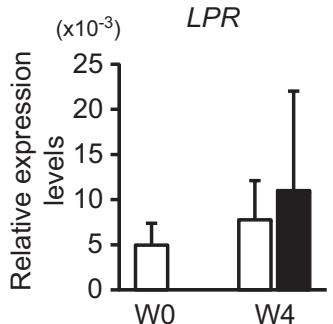

Figure 3 Effects of shrimp feed on relative expression levels of fatty acid regulatory genes in shrimp hepatopancreases. Shrimp hepatopancreases were collected at the beginning of the feed experiment when shrimp were only fed with feed pellets (W0, $n=18$ ) and again after shrimp were fed with either feed pellets (white bars, $n=9$ ) or polychaetes (black bars, $n=9$ ) for 4 weeks (W4). All shrimp samples contained stage 1 ovaries. Expression levels of fatty acid regulatory genes in shrimp hepatopancreases collected at W0 and W4 were determined using RT-qPCR and expressed relative to EF1A. Fatty acid regulatory genes include (A) SCD and (B) FASN in the fatty acid biosynthesis pathway; (C) LPR, (D) FATP1, (E) FATP4 and (F) FABP in the fatty acid transport pathway; and $(\mathrm{G})$ $A C A T,(\mathrm{H}) A C A D$ and (I) ECH in the fatty acid beta-oxidation pathway. Error bars indicate standard deviations. ${ }^{*}, *$ Significant differences between feed pellets and polychaetes at $P<$

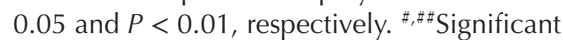
differences between the designated condition and the control at W0 at $P<0.05$ and $P<$ 0.01 , respectively.
(Fig. 6D, E, F, G, H and I). Nevertheless, the levels of $\mathrm{PGE}_{2}$ and $\mathrm{PGF}_{2 \alpha}$ in hepatopancreases of shrimp fed with polychaetes remained 15 and 12 times higher, respectively, than those fed with feed pellets (Fig. 6) and $\mathrm{K}$ ). As prostaglandin levels in hepatopancreases of polychaete-fed shrimp were higher than those of pelletfed shrimp in both intact and eyestalk-ablated samples, we speculate that the accumulation of prostaglandins in shrimp hepatopancreases were due to high levels of prostaglandins found in polychaetes. Eyestalk ablation did not affect the levels of prostaglandins in this organ.

The combination of shrimp feed and eyestalk ablation had minimal impact on fatty acid regulatory gene transcripts in shrimp hepatopancreases. In eyestalkablated shrimp with stage 2 ovaries, transcription levels of acyl-CoA dehydrogenase $(A C A D)$ were higher in hepatopancreases of shrimp fed with polychaetes compared to those fed with feed pellets (Fig. $7 \mathrm{H}$ ). The rest of the fatty acid regulatory genes showed similar transcription levels in hepatopancreases of shrimp in both feed groups (Fig. 7A, B, C, D, E, F, G and I).

\section{Combined effects of shrimp feed and eyestalk ablation on shrimp ovaries}

In eyestalk-ablated samples, levels of ARA and EPA were higher in ovaries of polychaete-fed shrimp compared to those of pellet-fed shrimp (Fig. 8A and B). Additionally, polychaete-fed shrimp with stage 1 ovaries exhibited higher transcription levels of COX and PGFS than those fed with feed pellets (Fig. 8E and I). At stage 2, transcription levels of PGES2 were higher in ovaries of polychaete-fed shrimp than those of pellet-fed shrimp (Fig. 8G). Enzyme immunoassays revealed that levels of $\mathrm{PGE}_{2}$ were comparable in ovaries of both feed groups while levels of $\mathrm{PGF}_{2 \alpha}$ were higher in stage 1 ovaries of pellet-fed shrimp compared to those of polychaete-fed shrimp (Fig. 8J and K).

Although higher transcription levels of fatty acid regulatory genes were detected in ovaries of intact polychaete-fed shrimp than those of pellet-fed shrimp, the reverse correlations were observed in ovaries of eyestalk-ablated samples. Transcription levels of $F A B P$, acetyl-CoA acetyltransferase (ACAT) and $A C A D$ were higher in stage 1 ovaries of pellet-fed shrimp than those of polychaete-fed shrimp (Fig. 9F, G and H). As shrimp ovaries progressed to stage 2, transcription levels of $S C D, \angle P R$ and FABP were higher in ovaries of pelletfed shrimp compared to those of polychaete-fed shrimp (Fig. 9A, C and F).

\section{Changes in hepatopancreases of polychaete-fed shrimp during ovarian maturation}

Aside from comparing differences between the two feed groups, data analysis was performed to assess changes in 
A

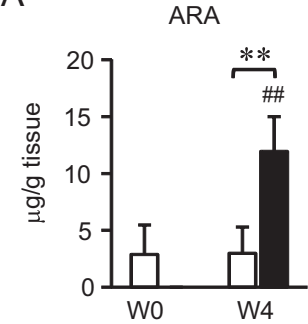

D

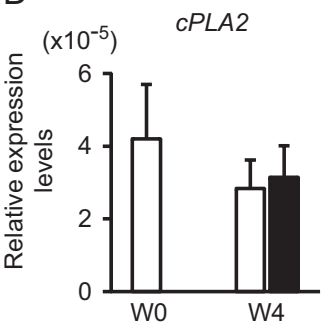

G
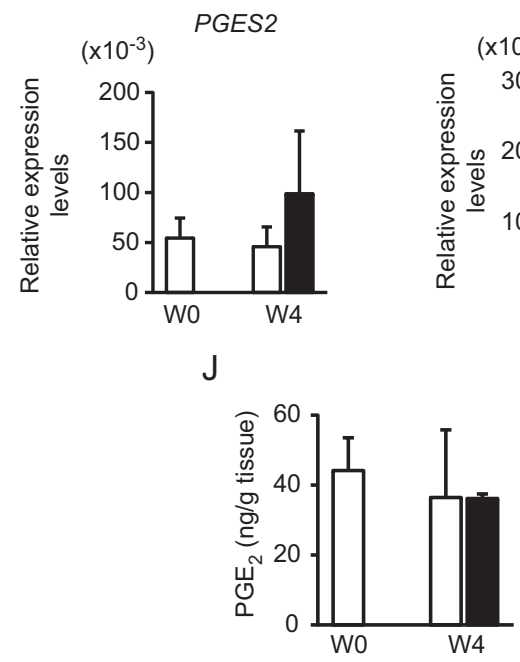

EPA

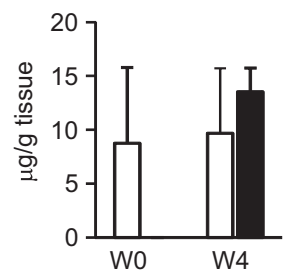

E

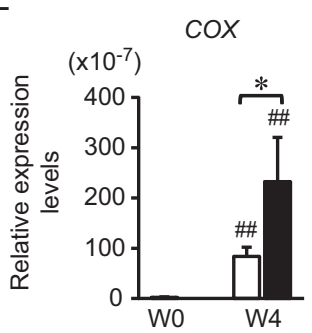

$\mathrm{H}$

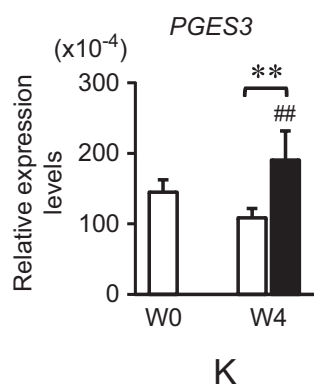

C

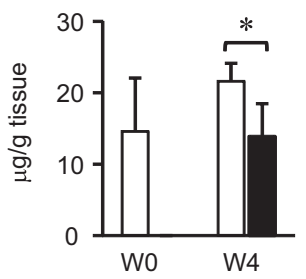

F

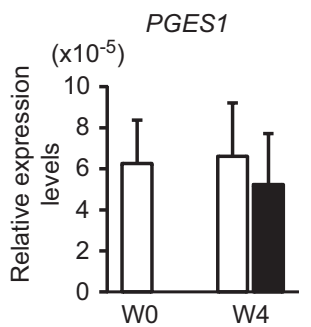

I

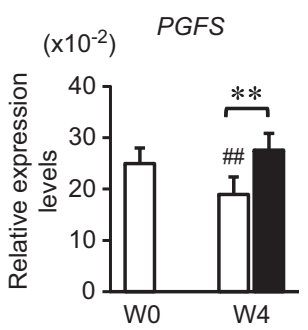

Figure 4 Effects of shrimp feed on prostaglandin biosynthesis pathway in shrimp ovaries. Shrimp ovaries were collected at the beginning of the feed experiment when shrimp were only fed with feed pellets (W0, $n=18$ ) and again after shrimp were fed with either feed pellets (white bars, $n=9$ ) or polychaetes (black bars, $n=9$ ) for 4 weeks (W4). All shrimp samples contained stage 1 ovaries. Levels of (A) ARA, (B) EPA and (C) DHA in ovaries were determined. Expression levels of (D) CPLA2, (E) COX, (F) PGES1, (G) PGES2, (H) PGES3 and (I) $P G F S$ in shrimp ovaries were determined using RT-qPCR and expressed relative to EF1A. Levels of $(\mathrm{J}) \mathrm{PGE}_{2}$ and $(\mathrm{K}) \mathrm{PGF}_{2 \alpha}$ in shrimp ovaries were determined using enzyme immunoassays. Error bars indicate standard deviations. ${ }^{* * *}$ Significant differences between feed pellets and polychaetes at $P<0.05$ and $P$ $<0.01$, respectively. ${ }^{\#, \# \text { Significant differences }}$ between the designated condition and the control at W0 at $P<0.05$ and $P<0.01$, respectively. the hepatopancreases of polychaete-fed shrimp during ovarian development. Compared to stage 1 ovaries, levels of DHA and EPA in hepatopancreases of polychaete-fed shrimp increased as shrimp reached stage 2 and 3 ovaries, respectively (Fig. 6B and C). Transcription levels of PGES1 in hepatopancreases were also highest in shrimp with stage 2 ovaries (Fig. 6F). In contrast, transcription levels of CPLA2, COX, PGES2, PGES3 and PGFS decreased as ovaries matured (Fig. 6D, E, G, H and I). Levels of $\mathrm{PGE}_{2}$ and $\mathrm{PGF}_{2 \alpha}$ in the hepatopancreases of polychaete-fed shrimp remained unchanged throughout ovarian development (Fig. 6J and K). Additionally, transcription levels of FASN, $\angle P R, F A B P$ and $A C A D$ decreased while transcription levels of $S C D$ and FATP1 increased in shrimp hepatopancreases during ovarian development (Fig. 7A, B, C, D, F and H).

\section{Changes in ovaries of polychaete-fed shrimp during ovarian maturation}

In ovaries of eyestalk-ablated, polychaete-fed shrimp, levels of ARA and EPA were highest in shrimp with stage 1 ovaries and decreased as ovaries matured (Fig. $8 \mathrm{~A}$ and $\mathrm{B})$. Transcription levels of CPLA2, PGES1, PGES2, and $P G E S 3$ increased as ovaries progressed from stage 1 to 4 (Fig. 8D, F, G and $\mathrm{H}$ ). In contrast, levels of $\mathrm{PGE}_{2}$ in ovaries decreased while levels of $\mathrm{PGF}_{2 \alpha}$ remained unchanged during ovarian development (Fig. 8J and K). Transcription levels of seven fatty acid regulatory genes, namely SCD, FASN, FATP1, FABP, ACAT, $A C A D$ and $E C H$, increased while transcription levels of $\angle P R$ and FATP4 decreased in ovaries during ovarian development (Fig. 9).

\section{Discussion}

Several nutritional factors, including proteins, PUFAs, carbohydrates and vitamins, contribute to successful ovarian development in crustaceans (Castille \& Lawrence 1989, Xu et al. 1994, Cahu et al. 1995, Wouters et al. 2001). Previous studies propose that polychaetes contain higher levels of signaling molecules and hormones, such as prostaglandins and 
A
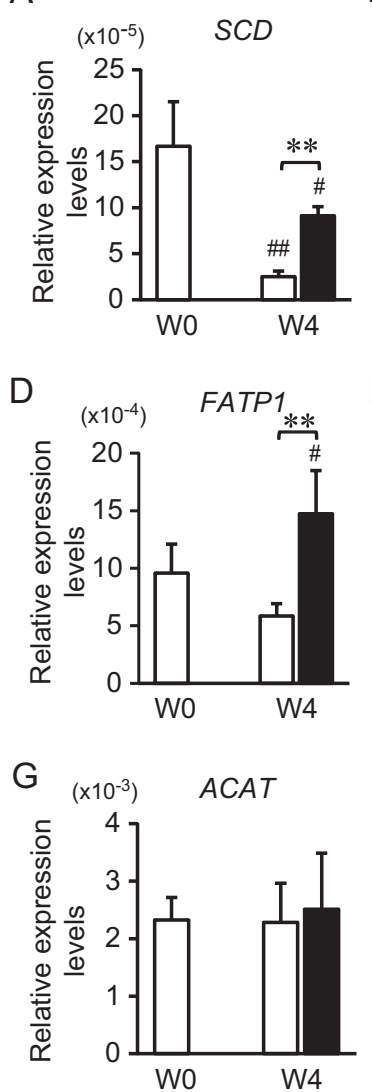

A

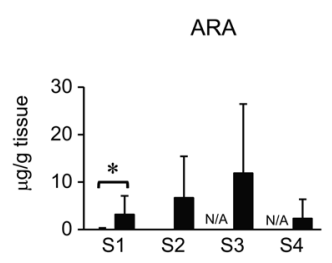

D
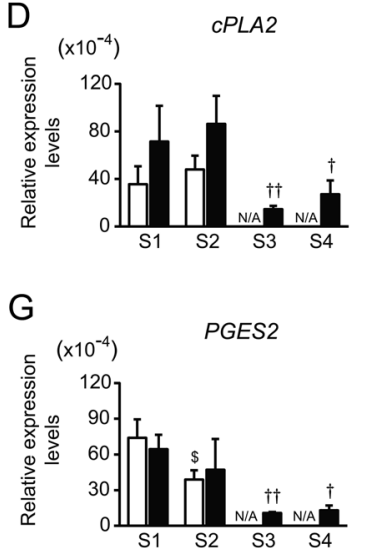

$\mathrm{H}$

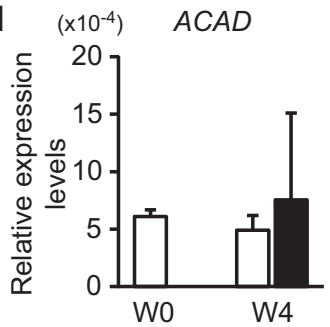

B

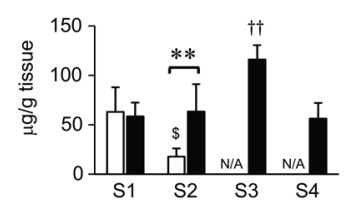

E
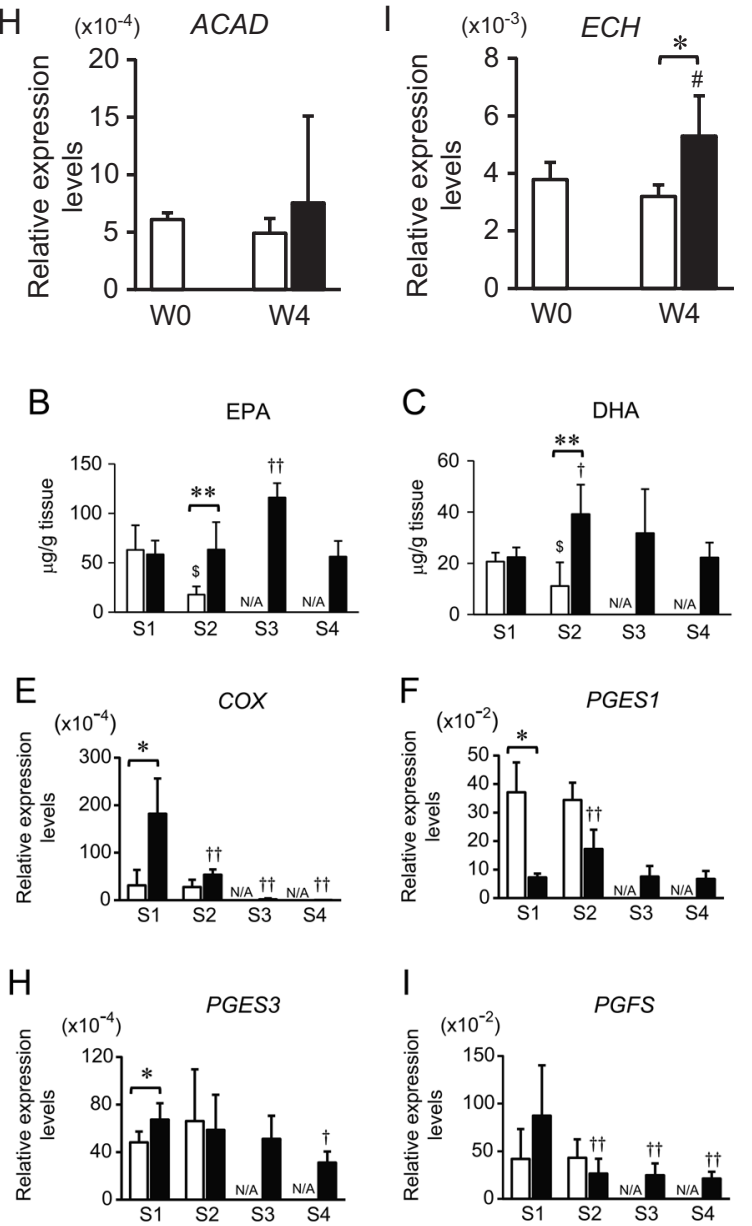

F

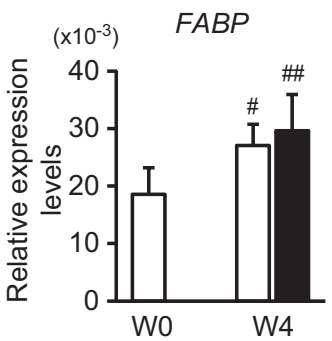

C

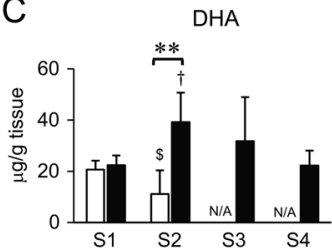

$\mathrm{F}$
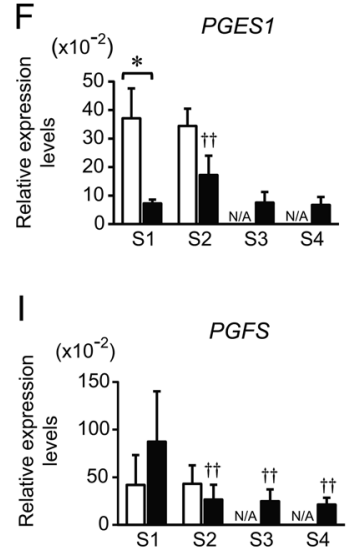

$\mathrm{K}$

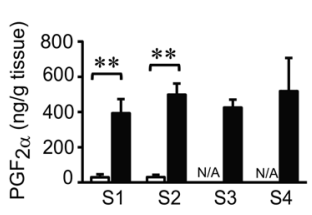

Figure 5 Effects of shrimp feed on relative expression levels of fatty acid regulatory genes in shrimp ovaries. Shrimp ovaries were collected at the beginning of the feed experiment when shrimp were only fed with feed pellets (W0, $n=18$ ) and again after shrimp were fed with either feed pellets (white bars, $n=9$ ) or polychaetes (black bars, $n=9$ ) for 4 weeks (W4). All shrimp samples contained stage 1 ovaries. Expression levels of fatty acid regulatory genes in shrimp ovaries collected at W0 and W4 were determined using RT-qPCR and expressed relative to EF1A. Fatty acid regulatory genes include (A) $S C D$ and (B) FASN in the fatty acid biosynthesis pathway; (C) LPR, (D) FATP1, (E) FATP4 and (F) $F A B P$ in the fatty acid transport pathway; and (G) ACAT, (H) ACAD and (I) $E C H$ in the fatty acid beta-oxidation pathway. Error bars indicate standard deviations. ${ }^{*}, *$ Significant differences between feed pellets and polychaetes at $P<0.05$ and $P<0.01$, respectively. ${ }^{\#, \# \text { Significant differences }}$ between the designated condition and the control at W0 at $P<0.05$ and $P<0.01$, respectively.

Figure 6 Combined effects of shrimp feed and eyestalk ablation on prostaglandin biosynthesis pathway in shrimp

hepatopancreases. Eyestalk-ablated shrimp that had previously been fed with feed pellets (white bars) or polychaetes (black bars) were grouped based on ovarian maturation stages (S1 for stage 1, S2 for stage 2, S3 for stage 3 and S4 for stage 4). Levels of (A) ARA, (B) EPA and (C) DHA in hepatopancreases were determined. Expression levels of (D) CPLA2, (E) COX, (F) PGES1, (G) PGES2, (H) PGES3 and (I) $P G F S$ in shrimp hepatopancreases were determined using RT-qPCR and expressed relative to $E F 1 A$. Levels of $(J) \mathrm{PGE}_{2}$ and $(\mathrm{K})$ $\mathrm{PGF}_{2 \alpha}$ in shrimp hepatopancreases were determined using enzyme immunoassays. Error bars indicate standard deviations. ${ }^{*, * *}$ Significant differences between feed pellets and polychaetes at $P<0.05$ and $P<0.01$, respectively. ${ }^{\$, \$}$ Significant differences between the marked condition and the pellet-fed shrimp at W4EAS1 at $P<0.05$ and $P<0.01$, respectively. ${ }^{t,++}$ Significant differences between the marked condition and the polychaete-fed shrimp at W4EAS1 at $P<0.05$ and $P<0.01$, respectively. N/A indicates that shrimp samples were not available for that stage. 

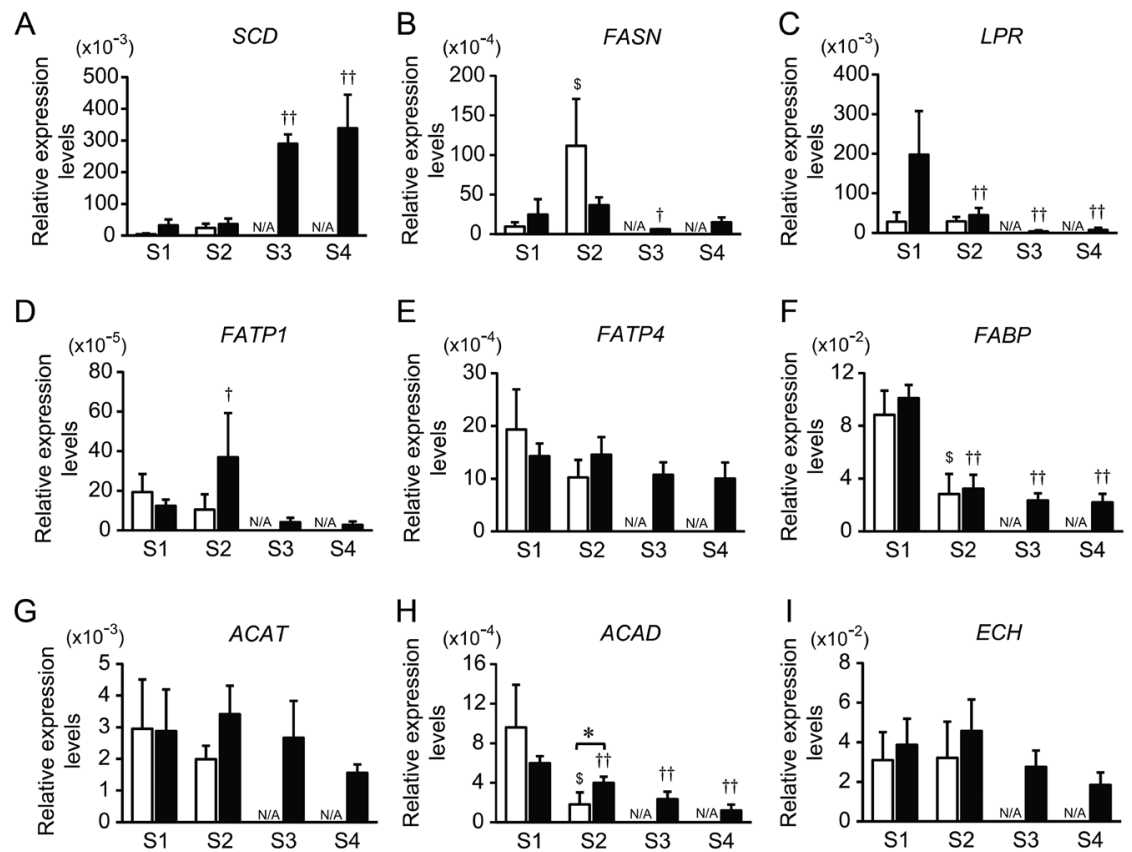

A

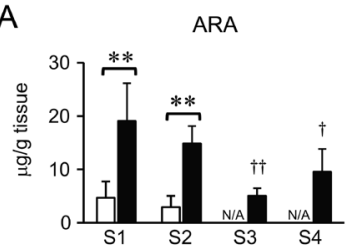

D
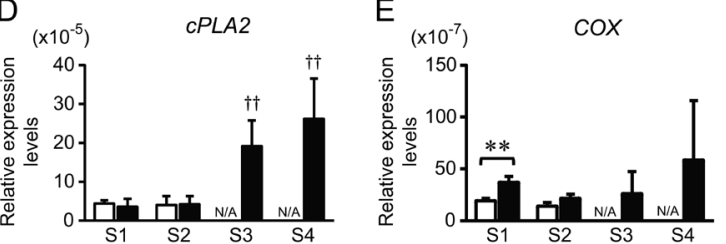

B

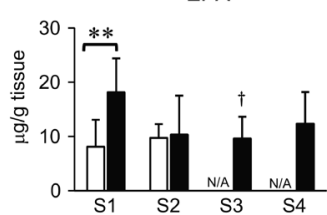

E

$\mathrm{H}$
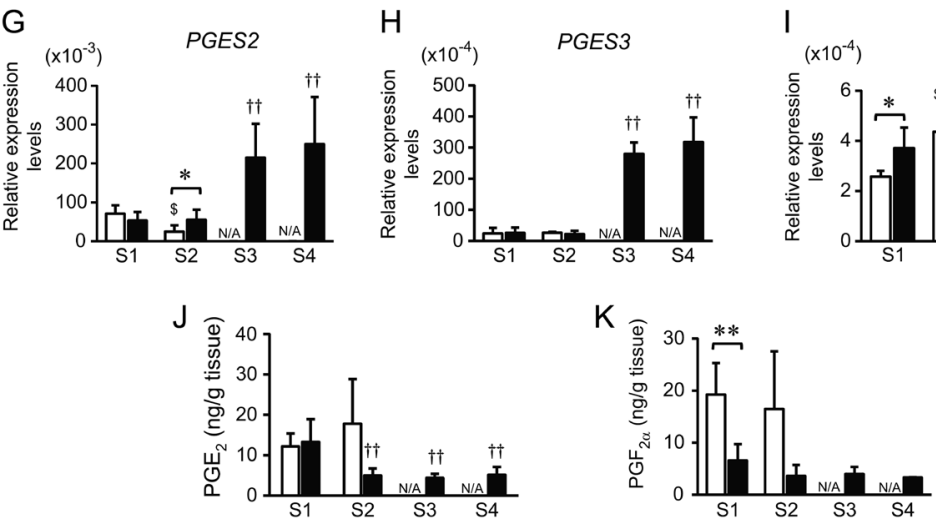

I $\left(\mathrm{x} 10^{-4}\right) \quad P G F S$

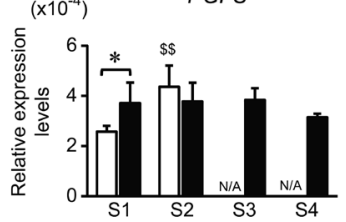

Figure 7 Combined effects of shrimp feed and eyestalk ablation on fatty acid regulatory genes in shrimp hepatopancreases. Eyestalkablated shrimp that had previously been fed with feed pellets (white bars) or polychaetes (black bars) were grouped based on ovarian maturation stages ( $\mathrm{S} 1$ for stage 1, S2 for stage 2, S3 for stage 3 and S4 for stage 4). Expression levels of fatty acid regulatory genes in ovaries of eyestalk-ablated shrimp were determined using RT-qPCR and expressed relative to $E F 1 A$. Fatty acid regulatory genes include (A) SCD and (B) FASN in the fatty acid biosynthesis pathway; (C) LPR, (D) FATP1, (E) FATP4 and (F) FABP in the fatty acid transport pathway; and (G) ACAT, (H) ACAD and (I) $E C H$ in the fatty acid beta-oxidation pathway. Error bars indicate standard deviations.

$*, * *$ Significant differences between feed pellets and polychaetes at $P<0.05$ and $P<$ 0.01 , respectively. $\$, \$ \$$ indicate significant differences between the marked condition and the pellet-fed shrimp at W4EAS1 at $P<0.05$ and $P<0.01$, respectively. ${ }^{t,+t}$ Significant differences between the marked condition and the polychaete-fed shrimp at W4EAS1 at $P<$ 0.05 and $P<0.01$, respectively. N/A indicates that shrimp samples were not available for that stage.
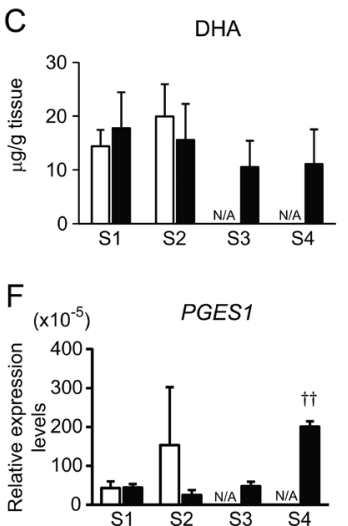

Figure 8 Combined effects of shrimp feed and eyestalk ablation on prostaglandin biosynthesis in shrimp ovaries. Eyestalkablated shrimp that had previously been fed with feed pellets (white bars) or polychaetes (black bars) were grouped based on ovarian maturation stages (S1 for stage 1, S2 for stage 2, S3 for stage 3 and S4 for stage 4). Levels of (A) ARA, (B) EPA and (C) DHA in ovaries were determined. Expression levels of (D) CPLA2, (E) COX, (F) PGES1, (G) PGES2, (H) PGES3 and (I) $P G F S$ in shrimp ovaries were determined using RT-qPCR and expressed relative to EF1A. Levels of (J) $\mathrm{PGE}_{2}$ and (K) $\mathrm{PGF}_{2 \alpha}$ in shrimp ovaries were determined using enzyme immunoassays. Error bars indicate standard deviations. *,* Significant differences between feed pellets and polychaetes at $P<0.05$ and $P<0.01$, respectively. ${ }^{\$, \$}$ Significant differences between the marked condition and the pellet-fed shrimp at W4EAS1 at $P<0.05$ and $P<0.01$, respectively. ${ }^{t+t}$ Significant differences between the marked condition and the polychaete-fed shrimp at W4EAS1 at $P<$ 0.05 and $P<0.01$, respectively. N/A indicates that shrimp samples were not available for that stage. 

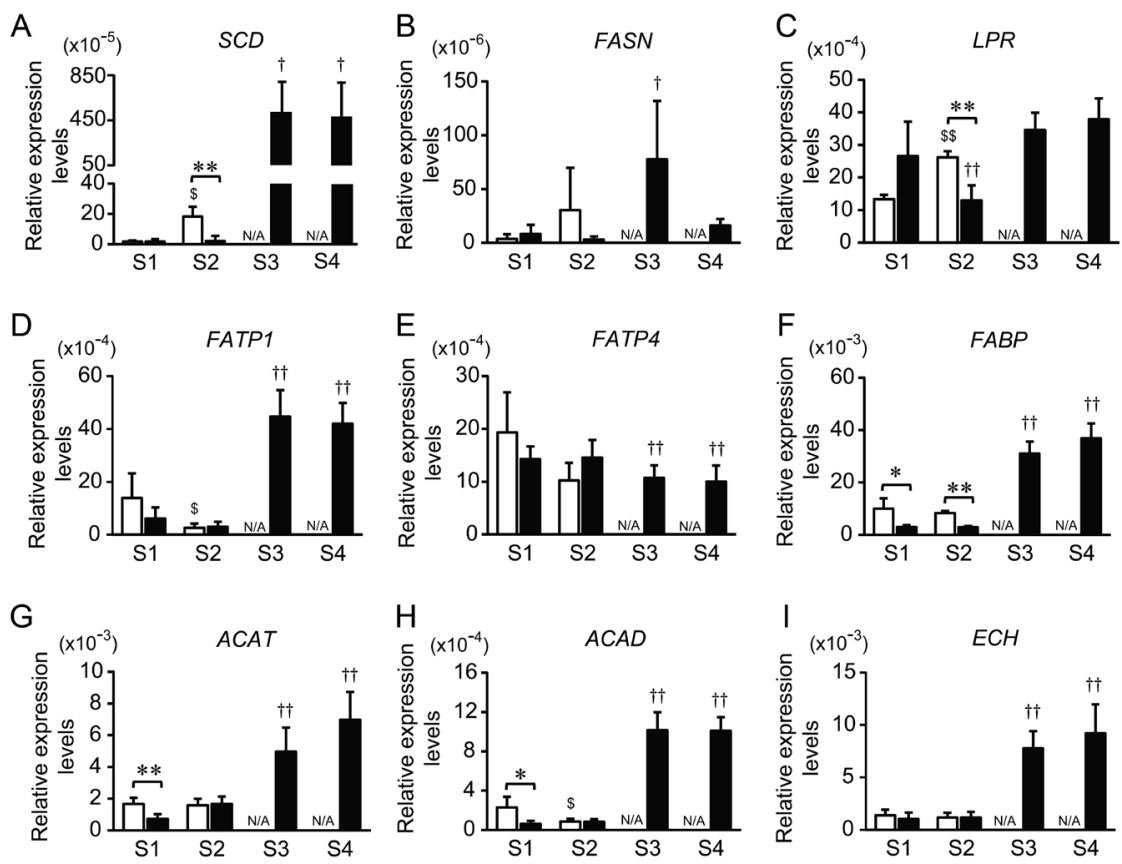

Figure 9 Combined effects of shrimp feed and eyestalk ablation on fatty acid regulatory genes in shrimp ovaries. Eyestalk-ablated shrimp that had previously been fed with feed pellets (white bars) or polychaetes (black bars) were grouped based on ovarian maturation stages (S1 for stage 1, S2 for stage 2, S3 for stage 3 and $S 4$ for stage 4). Expression levels of fatty acid regulatory genes in ovaries of eyestalk-ablated shrimp were determined using RT-qPCR and expressed relative to EF1A. Fatty acid regulatory genes include (A) $S C D$ and (B) FASN in the fatty acid biosynthesis pathway; (C) LPR, (D) FATP1, (E) FATP4 and (F) $F A B P$ in the fatty acid transport pathway; and (G) $A C A T,(\mathrm{H}) A C A D$ and (I) $E C H$ in the fatty acid beta-oxidation pathway. Error bars indicate standard deviations. ${ }^{* * *}$ Significant differences between feed pellets and polychaetes at $P<0.05$ and $P<0.01$, respectively. ${ }^{\$, \$}$ Significant differences between the marked condition and the pellet-fed shrimp at W4EAS1 at $P<0.05$ and $P<0.01$, respectively. ${ }^{t,+t}$ Significant differences between the marked condition and the polychaete-fed shrimp at W4EAS1 at $P<$ 0.05 and $P<0.01$, respectively. N/A indicates that shrimp samples were not available for that stage. progesterone, which are responsible for successful ovarian development in crustaceans (Reddy et al. 2004, Meunpol et al. 2007, 2010). In this study, changes in the prostaglandin biosynthesis pathway of shrimp fed with feed pellets and polychaetes were examined as the effects of shrimp feed alone or in combination with eyestalk ablation. Additionally, transcriptional changes of fatty acid regulatory genes were examined to determine the connection between shrimp diet, prostaglandins and fatty acid regulatory pathways in $P$. monodon.

\section{Polychaete feeding and the levels of PUFAs and prostaglandins in crustaceans}

A study in M.japonicus showed that hepatopancreases of polychaete-fed shrimp contained larger amounts of ARA than those of pellet-fed shrimp (Binh et al. 2008). In male P. monodon, consumption of natural diets comprised of polychaetes, squid and mussels also resulted in larger amounts of ARA in shrimp hepatopancreases when compared to those fed with commercial feed pellets (Meunpol et al. 2005). Similarly, our study showed that ovaries of shrimp fed with polychaetes showed higher levels of ARA and higher transcription levels of COX and PGFS than those of pellet-fed shrimp. However, the levels of $\mathrm{PGE}_{2}$ and $\mathrm{PGF}_{2 \alpha}$ in ovaries did not share the same correlation. We speculate that $\mathrm{PGE}_{2}$ and $\mathrm{PGF}_{2 \alpha}$ were quickly synthesized and then converted to downstream metabolites by enzymes such as prostaglandin reductase 1 (Prasertlux et al. 2011). Therefore, the levels of these prostaglandins did not change significantly when detected with enzyme immunoassays.

In hepatopancreases, high levels of ARA and EPA in polychaetes resulted in higher levels of ARA and EPA in hepatopancreases of eyestalk-ablated, polychaetefed shrimp compared to those of pellet-fed shrimp. This corresponded with increased transcription levels of COX and PGES3 in shrimp hepatopancreases. Additionally, high levels of $\mathrm{PGE}_{2}$ and $\mathrm{PGF}_{2 \alpha}$ in polychaetes also correlated with higher levels of $\mathrm{PGE}_{2}$ and $\mathrm{PGF}_{2 \alpha}$ in hepatopancreases of polychaete-fed shrimp compared to those of pellet-fed shrimp.

\section{PUFAs, prostaglandins and ovarian development}

As ovarian maturation progressed, the amounts of ARA and EPA decreased while the amount of DHA increased in the banana shrimp Penaeus merguiensis (Chansela et al. 2012). Reduction of ARA and EPA levels was also observed as $P$. monodon ovaries matured. On the other hand, different levels of prostaglandins in ovaries have been shown to correlate with ovarian development in crustaceans, including $P$. monodon, M. rosenbergii, P. paeninsulanus, M. japonicus and $O$. senex senex (Spaziani et al. 1993, Reddy et al. 2004, Tahara \& Yano 2004, Meunpol et al. 2010, Wimuttisuk et al. 2013, Sumpownon et al. 2015). Levels of $\mathrm{PGE}_{2}$ in ovaries decreased in M. japonicus and $M$. rosenbergii, but increased in $P$. paeninsulanus, $O$. senex senex and wild $P$. monodon during ovarian development 
(Spaziani et al. 1993, Reddy et al. 2004, Tahara \& Yano 2004, Meunpol et al. 2010, Wimuttisuk et al. 2013, Sumpownon et al. 2015). On the other hand, levels of $\mathrm{PGE}_{2}$ in domesticated $P$. monodon ovaries decreased as ovaries matured, suggesting opposing correlations between wild and domesticated shrimp. Therefore, it is unlikely that the level of $\mathrm{PGE}_{2}$ in ovaries is the determining factor for successful ovarian development.

Changes in the transcription levels of prostaglandin biosynthesis genes have previously been reported in two studies. In the female mud crab Scylla olivacea, PGES levels significantly increased from stage 1 to stage 4 ovaries (Duangprom et al. 2018). In wild $P$. monodon, transcription levels of PGES1 increased while transcription levels of PGES2 and PGFS decreased in shrimp ovaries during ovarian development (Wimuttisuk et al. 2013). In this study, transcription levels of prostaglandin biosynthesis genes in ovaries of polychaete-fed shrimp increased, while levels of $\mathrm{PGE}_{2}$ decreased as ovarian maturation progressed. Although this suggests opposing correlations at the transcription and metabolic levels, the decreasing levels of $\mathrm{PGE}_{2}$ corresponded with decreasing levels of ARA in shrimp ovaries. Therefore, the levels of prostaglandins were likely regulated by the availability of the precursor ARA rather than the levels of prostaglandin gene transcripts.

\section{Effects of shrimp diet and ovarian maturation on fatty acid regulatory genes}

Changes in crustacean diet have previously been shown to affect transcription levels of fatty acid regulatory genes, including FABP, FASN and SCD in E. sinensis and P. vannamei (Wen et al. 2001, Guo et al. 2013, Chen et al. 2015, Wei et al. 2017). In P. monodon, transcription levels of SCD, LPR, FATP1, FATP4 and ECH increased while transcription levels of FASN decreased in ovaries of polychaete-fed shrimp compared to those of pelletfed shrimp. Both SCD and FASN are part of the fatty acid synthesis pathway, in which $S C D$ regulates the ratelimiting step of monounsaturated fatty acids synthesis while FASN is crucial for long-chain fatty acid synthesis (Enoch et al. 1976, Chakravarty et al. 2004). Studies have shown that $S C D$ mRNA stability is regulated by dietary PUFAs and cholesterols while transcription levels of FASN were found to be reduced in hamsters on a high fat diet (Ntambi 1999, Field et al. 2003) Therefore, the impact of shrimp diet on SCD and FASN transcripts indicates that this regulatory mechanism is also conserved in crustaceans.

During P. monodon ovarian development, transcription levels of $A C A T, A C A D$ and $E C H$ increased in shrimp ovaries. These genes are part of the fatty acid beta-oxidation pathway, which metabolizes fatty acids for ATP production (Houten \& Wanders 2010). Our data

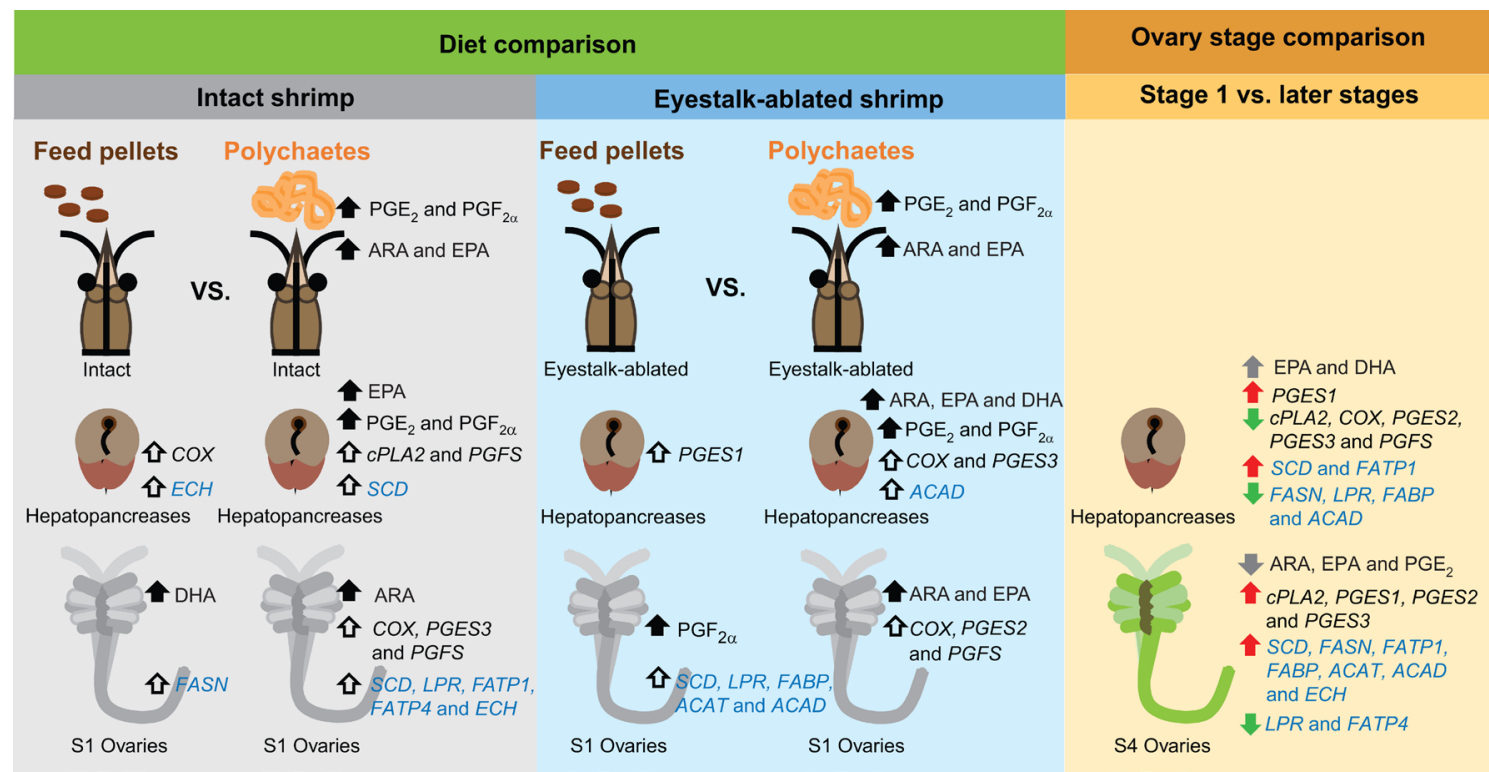

Figure 10 Summary of the effects of shrimp feed on prostaglandin biosynthesis and fatty acid regulatory pathways in $P$. monodon. The left panel illustrates the effects of shrimp feed on intact shrimp. The middle panel represents the combined effects of shrimp feed and eyestalk ablation on shrimp hepatopancreases and ovaries. Changes in polychaete-fed shrimp during ovarian development are shown in the right panel. Black arrows indicate higher levels of PUFAs and prostaglandins compared to the other feed group. White arrows indicate higher transcription levels of the designated gene compared to those in shrimp from the other feed group. Gray arrows point up or down indicate that the levels of PUFAs and $\mathrm{PGE}_{2}$ in the designated organ increased or decreased, respectively, as ovaries matured. Red and green arrows represent higher and lower transcription levels of genes as ovarian maturation progressed compared to eyestalk-ablated, polychaete-fed shrimp with stage 1 ovaries, respectively. 
correspond with results from other studies that fatty acid beta-oxidation is up-regulated in ovaries during ovarian development due to increased energy requirements (Paczkowski et al. 2013, Dunning et al. 2014, Deenarn et al. 2018).

\section{Dynamics of prostaglandin biosynthesis and fatty acid regulatory pathways in $P$. monodon}

The effects of polychaete consumption on shrimp prostaglandin biosynthesis and fatty acid regulatory pathways in this study can be categorized into three stages: (1) in intact shrimp after 4 weeks of feeding, (2) in eyestalk-ablated shrimp, and (3) changes that occurred in polychaete-fed shrimp during ovarian development (Fig. 10). Intact shrimp fed with polychaetes contained higher levels of EPA, $\mathrm{PGE}_{2}$ and $\mathrm{PGF}_{2 \alpha}$ in their hepatopancreases than pellet-fed shrimp. However, the difference in shrimp feed had minor effects on the transcription levels of prostaglandin biosynthesis and fatty acid regulatory genes in shrimp hepatopancreases. On the other hand, ovaries of polychaete-fed shrimp contained higher levels of ARA but lower levels of DHA than those of pelletfed shrimp. The transcription levels of prostaglandin biosynthesis and fatty acid regulatory genes generally increased in ovaries of polychaete-fed shrimp compared to those of pellet-fed shrimp.

After eyestalk ablation was performed, levels of ARA, EPA, DHA, $\mathrm{PGE}_{2}$ and $\mathrm{PGF}_{2 \alpha}$ in hepatopancreases of polychaete-fed shrimp were higher than those fed with feed pellets. Most prostaglandin biosynthesis and fatty acid regulatory genes in hepatopancreases were unaffected by the difference in shrimp feed. Ovaries of eyestalkablated, polychaete-fed shrimp contained higher levels of ARA and EPA, but lower levels of PGF ${ }_{2 \alpha}$ than those of pellet-fed shrimp. Prostaglandin biosynthesis and fatty acid regulatory genes in ovaries of eyestalk-ablated shrimp showed opposing transcriptional patterns, with transcription levels of prostaglandin biosynthesis genes being higher in ovaries of polychaete-fed shrimp and transcription levels of fatty acid regulatory genes being higher in ovaries of pellet-fed shrimp.

Lastly, transcription and metabolic changes were monitored in polychaete-fed shrimp as ovary development progressed from stage 1 to stage 4 . In hepatopancreases, levels of EPA and DHA increased while transcriptional levels of prostaglandin biosynthesis and fatty acid regulatory genes decreased as ovarian maturation progressed. In shrimp ovaries, however, levels of $A R A, E P A$ and $P E_{2}$ decreased but transcription levels of most prostaglandin biosynthesis and fatty acid regulatory genes increased as ovaries matured. Together, our results indicate that polychaete feeding induced the prostaglandin biosynthesis pathway in $P$. monodon. The dynamics between prostaglandin biosynthesis and fatty acid regulatory pathways in shrimp ovaries and hepatopancreas were observed at various stages during ovarian maturation, providing insight into the transcription and metabolic changes that occur in crustaceans before and during ovarian development. Lastly, our data suggests a new strategy for feed formulation, in which higher amounts of ARA, EPA, $\mathrm{PGE}_{2}$ and $\mathrm{PGF}_{2 \alpha}$ in feed pellets are imperative to induce successful ovarian development.

\section{Supplementary materials}

This is linked to the online version of the paper at https://doi. org/10.1530/REP-20-0217.

\section{Declaration of interest}

The authors declare that there is no conflict of interest that could be perceived as prejudicing the impartiality of the research reported.

\section{Funding}

This work was supported by the National Science and Technology Development Agency (grant numbers P-11-01054 and P-13-50373); the Thailand Research Fund under the TRF mid-career research grant (grant number RSA6180007) and partially supported by the European Union's Horizon 2020 research and 523 innovation program under the Marie Skłodowska-Curie (grant number 734486).

\section{Author contribution statement}

P D and P T performed experiments and analyzed data. V V and $R \mathrm{~L}$ planned experiments and revised the paper. S $\mathrm{P}$ and P C conducted shrimp feed trials. W W planned and performed experiments, analyzed data and wrote the paper.

\section{Acknowledgements}

The authors would thank Somjai Wongtripop for her expertise in shrimp rearing. The authors would thank Wishcha Ngarmboonanant and Dr Samaporn Teeravechyan for fruitful discussions.

\section{References}

Benzie JAH 1997 A review of the effect of genetics and environment on the maturation and larval quality of the giant tiger prawn Penaeus monodon. Aquaculture 155 69-85. (https://doi.org/10.1016/S00448486(97)00110-5)

Binh NT, Ishikawa M, Yokoyama S, Michael FR, Sakiyama K \& Shunsuke K 2008 Effects of polychaete meal supplementation to the maturation feed on kuruma shrimp (Penaeus japonicus) female broodstocks. Aquaculture Science 56 523-530. (https://doi.org/10.11233/aquaculturesci.56.523)

Cahu CL, Cuzon G \& Quazuguel P 1995 Effect of highly unsaturated fatty acids, $\alpha$-tocopherol and ascorbic acid in broodstock diet on egg composition and development of Penaeus indicus. Comparative Biochemistry and Physiology Part A 112 417-424. (https://doi. org/10.1016/0300-9629(95)02009-8)

Castille FL \& Lawrence AL 1989 Relationship between maturation and biochemical composition of the gonads and digestive glands of the 
shrimps Penaeus aztecus Ives and Penaeus setiferus (L.). Journal of Crustacean Biology 9 202. (https://doi.org/10.1163/193724089X00025) Chakravarty B, Gu Z, Chirala SS, Wakil SJ \& Quiocho FA 2004 Human fatty acid synthase: structure and substrate selectivity of the thioesterase domain. PNAS 101 15567-15572. (https://doi.org/10.1073/ pnas.0406901101)

Chansela P, Goto-Inoue N, Zaima N, Hayasaka T, Sroyraya M, Kornthong N, Engsusophon A, Tamtin M, Chaisri C, Sobhon P et al. 2012 Composition and localization of lipids in Penaeus merguiensis ovaries during the ovarian maturation cycle as revealed by imaging mass spectrometry. PLOS ONE 7 e33154. (https://doi.org/10.1371/journal.pone.0033154)

Chen K, Li E, Xu Z, Li T, Xu C, Qin JG \& Chen L 2015 Comparative transcriptome analysis in the hepatopancreas tissue of pacific white shrimp Litopenaeus vannamei fed different lipid sources at low salinity. PLOS ONE 10 e0144889. (https://doi.org/10.1371/journal.pone.0144889)

Chimsung N 2014 Maturation diets for black tiger shrimp (Penaeus monodon) broodstock: a review. Songklanakarin Journal of Science and Technology 36 265-273.

Deenarn P, Tobwor P, Leelatanawit R, Wongtriphop S, Khudet J, Karoonuthaisiri N, Vichai V \& Wimuttisuk W 2018 Dynamics of fatty acid regulatory genes during ovarian development in Penaeus monodon. Reproduction 156 527-544. (https://doi.org/10.1530/REP-18-0143)

DeVries JW, Kjos L, Groff L, Bob M, Kristi C, Patel H, Payne M, Leichtweis H, Shay M \& Newcomer L 1999 Studies in improvement of official method 996.06. Journal of AOAC International 82 1146-1155. (https://doi.org/10.1093/jaoac/82.5.1146)

Duangprom S, Ampansri W, Suwansa-ard S, Chotwiwatthanakun C, Sobhon P \& Kornthong N 2018 Identification and expression of prostaglandin E synthase (PGES) gene in the central nervous system and ovary during ovarian maturation of the female mud crab, Scylla olivacea. Animal Reproduction Science 198 220-232. (https://doi.org/10.1016/j. anireprosci.2018.09.022)

Dunning KR, Russell DL \& Robker RL 2014 Lipids and oocyte developmental competence: the role of fatty acids and $\beta$-oxidation. Reproduction 148 R15-R27. (https://doi.org/10.1530/REP-13-0251)

Elwood RW, Barr S \& Patterson L 2009 Pain and stress in crustaceans? Applied Animal Behaviour Science 118 128-136. (https://doi. org/10.1016/j.applanim.2009.02.018)

Enoch HG, Catalá A \& Strittmatter P 1976 Mechanism of rat liver microsomal stearyl-CoA desaturase. Studies of the substrate specificity, enzyme-substrate interactions, and the function of lipid. Journal of Biological Chemistry 251 5095-5103.

Field FJ, Born E \& Mathur SN 2003 Fatty acid flux suppresses fatty acid synthesis in hamster intestine independently of SREBP-1 expression. Journal of Lipid Research 44 1199-1208. (https://doi.org/10.1194/jlr. M300013-JLR200)

Guo ZH, Yang ZG, Cheng YX, Ji LY, Que YQ, Liu ZW \& Zeng QT 2013 Molecular characterization, tissue expression of acyl-CoA $\delta 9$-desaturaselike gene, and effects of dietary lipid levels on its expression in the hepatopancreas of the Chinese mitten crab (Eriocheir sinensis). Aquaculture 42-43 58-65. (https://doi.org/10.1016/j.aquaculture.2013.03.033)

Houten SM \& Wanders RJA 2010 A general introduction to the biochemistry of mitochondrial fatty acid $\beta$-oxidation. Journal of Inherited Metabolic Disease 33 469-477. (https://doi.org/10.1007/s10545-010-9061-2)

Kilkenny C, Browne WJ, Cuthill IC, Emerson M \& Altman DG 2010 Improving bioscience research reporting: the ARRIVE guidelines for reporting animal research. PLoS Biology 8-5 e1000412. (https://doi. org/10.1371/journal.pbio.1000412)

Meunpol O, Meejing P \& Piyatiratitivorakul S 2005 Maturation diet based on fatty acid content for male Penaeus monodon (Fabricius) broodstock. Aquaculture Research 36 1216-1225. (https://doi.org/10.1111/j.13652109.2005.01342.x)

Meunpol O, Iam-Pai S, Suthikrai W \& Piyatiratitivorakul S 2007 Identification of progesterone and $17 \alpha$-hydroxyprogesterone in polychaetes (Perinereis sp.) and the effects of hormone extracts on penaeid oocyte development in vitro. Aquaculture 270 485-492. (https://doi.org/10.1016/j.aquaculture.2007.05.031)

Meunpol O, Duangjai E, Yoonpun R \& Piyatiratitivorakul S 2010 Detection of prostaglandin E2 in polychaete Perinereis sp. and its effect on Penaeus monodon oocyte development in vitro. Fisheries Science 76 281-286. (https://doi.org/10.1007/s12562-009-0208-8)

Ntambi JM 1999 Regulation of stearoyl-CoA desaturase by polyunsaturated fatty acids and cholesterol. Journal of Lipid Research 40 1549-1558.
Paczkowski M, Silva E, Schoolcraft WB and Krisher RL 2013 Comparative importance of fatty acid beta-oxidation to nuclear maturation, gene expression, and glucose metabolism in mouse, bovine, and porcine cumulus oocyte complexes 1. Biology of Reproduction 88 1-11. (https:// doi.org/10.1095/biolreprod.113.108548)

Prasertlux S, Sittikankaew K, Chumtong P, Khamnamtong B \& Klinbunga S 2011 Molecular characterization and expression of the prostaglandin reductase 1 gene and protein during ovarian development of the giant tiger shrimp Penaeus monodon. Aquaculture 322-323 134-141. (https:// doi.org/10.1016/j.aquaculture.2011.09.037)

Reddy PS, Reddy PRS \& Nagaraju GPC 2004 The synthesis and effects of prostaglandins on the ovary of the crab Oziotelphusa senex senex. General and Comparative Endocrinology 135 35-41. (https://doi. org/10.1016/j.ygcen.2003.08.002)

Spaziani EP, Hinsch GW \& Edwards SC 1993 Changes in prostaglandin $E_{2}$ and $F_{2 \alpha}$ during vitellogenesis in the florida crayfish Procambarus paeninsulanus. Journal of Comparative Physiology B 163 541-545. (https://doi.org/10.1007/BF00302112)

Sumpownon C, Engsusophon A, Siangcham T, Sugiyama E, Soonklang N, Meeratana P, Wanichanon C, Hanna PJ, Setou M \& Sobhon P 2015 Variation of prostaglandin $E_{2}$ concentrations in ovaries and its effects on ovarian maturation and oocyte proliferation in the giant fresh water prawn, Macrobrachium rosenbergii. General and Comparative Endocrinology 223 129-138. (https://doi.org/10.1016/j.ygcen.2015.04.019)

Tahara D \& Yano I 2004 Maturation-related variations in prostaglandin and fatty acid content of ovary in the kuruma prawn (Marsupenaeus japonicus). Comparative Biochemistry and Physiology: Part A, Molecular and Integrative Physiology 137 631-637. (https://doi.org/10.1016/j.cbpb.2003.12.005)

Vogt G 1994 Life-cycle and functional cytology of the hepatopancreatic cells of Astacus astacus (Crustacea, Decapoda). Zoomorphology 114 83-101. (https://doi.org/10.1007/BF00396642)

Wei B, Yang Z, Wang J, Chen A, Shi Q \& Cheng Y 2017 Effects of dietary lipids on the hepatopancreas transcriptome of Chinese mitten crab (Eriocheir sinensis). PLOS ONE 12 e0182087. (https://doi.org/10.1371/ journal.pone.0182087)

Wen XB, Chen LQ, Ai CX, Zhou Z \& Jiang H 2001 Variation in lipid composition of Chinese mitten-handed crab, Eriocheir sinensis during ovarian maturation. Comparative Biochemistry and Physiology: Part B, Biochemistry and Molecular Biology 130 95-104. (https://doi. org/10.1016/s1096-4959(01)00411-0)

Wimuttisuk W, Tobwor P, Deenarn P, Danwisetkanjana K, Pinkaew D, Kirtikara K \& Vichai V 2013 Insights into the prostanoid pathway in the ovary development of the penaeid shrimp Penaeus monodon. PLOS ONE 8-15 e76934. (https://doi.org/10.1371/journal.pone.0076934)

Wimuttisuk W, Tobwor P, Deenarn P, Intaraudom C, Pruksatrakul T, Nithithanasilp S, Wongtripop S, Phomklad S, Chaitongsakul P \& Vichai V 2017 Differential regulation of the lipoxygenase pathway in shrimp hepatopancreases and ovaries during ovarian development in the black tiger shrimp Penaeus monodon. Biochemical and Biophysical Research Communications 487 396-402. (https://doi.org/10.1016/j. bbrc.2017.04.073)

Wouters R, Lavens P, Nieto J \& Sorgeloos P 2001 Penaeid shrimp broodstock nutrition: an updated review on research and development. Aquaculture 202 1-21. (https://doi.org/10.1016/S00448486(01)00570-1)

Xu XL, Ji WJ, Castell JD \& O'Dor RK 1994 Influence of dietary lipid sources on fecundity, egg hatchability and fatty acid composition of Chinese prawn (Penaeus chinensis) broodstock. Aquaculture 119 359-370. (https://doi.org/10.1016/0044-8486(94)90300-X)

Yuan Y, Sun P, Jin M, Wang X \& Zhou Q 2019 Regulation of dietary lipid sources on tissue lipid classes and mitochondrial energy metabolism of juvenile swimming crab, Portunus trituberculatus. Frontiers in Physiology 10 454. (https://doi.org/10.3389/fphys.2019.00454)

Received 19 April 2020

First decision 3 June 2020

Revised Manuscript received 2 September 2020

Accepted 10 September 2020 